\title{
TRANS MODEL MATHEMATICS EDUCATION (T2ME) UNTUK MENINGKATKAN KETERAMPILAN OPERASI HITUNG PERKALIAN BERBANTUAN TEKNIK SUBATSAGA DI SEKOLAH DASAR
}

\author{
Wilda Oktafiani, Miladi Rizkyah Budiarti, Solekha, Tia Fuja Yulistia, Oriza Mutia \\ Oktaviani, Suprih Widodo \\ Program Studi PGSD, Universitas Pendidikan Indonesia, Kampus Purwakarta
}

\section{Kata Kunci :}

Perkalian

Trans Model Mathematics Education (T2ME)

Teknik SuBatSaGa

\section{Email penulis:}

wildaoktafiani@student.upi.edu

\begin{abstract}
This research is motivated by the low ability to solve various multiplication problem that occurred in the $4^{\text {th }}$ grade in Elementary School (SD). This data was obtained based on observation and interviews conducted with classroom teachers at some public Elementary Schools in Purwakarta. In one of the public Elementary Schools it was found that only $25 \%$ of students were able control multiplication. Based on the problems, the research method use is Research and Development (R\&D) Borg and Gall. Product design that will be developed and applied that is model of learning model of mathematics education model (T2ME) and technique of SuBatSaGa multiplication. Our Product design developed has been approved by the experts. The experts in this research that is lecturer of mathematics.
\end{abstract}

\begin{abstract}
ABSTRAK
Penelitian ini dilatarbelakangi oleh masih rendahnya kemampuan dalam menyelesaikan masalah-masalah perkalian yang terjadi pada kelas IV (empat) Sekolah Dasar (SD). Data ini diperoleh berdasarkan hasil observasi dan wawancara yang dilakukan dengan guru kelas pada beberapa SD Negeri di Kabupaten Purwakarta. Pada salah satu SD Negeri ditemukan data bahwa hanya $25 \%$ dari jumlah siswa yang mampu menguasai perkalian. Berdasarkan permasalahan maka metode penelitian yang digunkanan yaitu metode penelitian Research and Development (R\&D) Borg and Gall. Desain produk yang akan dikembangkan dan diaplikasikan yaitu model pembelajaran Trans Model Mathematics Education (T2ME) dan teknik penyelesaian perkalian SuBatSaGa (Susun bawah, Batang Napier, Saringan, Garis). Desain produk yang kami kembangkan telah disetujui oleh pakar/ahli. Ahli dalam penelitian ini yaitu dosen matematika.
\end{abstract}

\section{PENDAHULUAN}

Matematika merupakan suatu ilmu wajib yang harus dipelajari dan dikuasai oleh siswa Sekolah Dasar. Hal ini tertuang dalam Peraturan Menteri Pendidikan Nasional Nomor 22 Tahun 2006 Tentang Standar Isi, dalam peraturan tersebut menyatakan bahwa, "matematika merupakan kelompok ilmu pengetahuan dan teknologi tujuannya yaitu supaya siswa 
mengenal, menyikapi, dan mengapresiasi ilmu pengetahuan dan teknologi, serta menanamkan kebiasaan berpikir dan berperilaku ilmiah yang kritis, kreatif dan mandiri". Urgensi dalam mempelajari matematika yaitu dikarenakan konsep-konsep pada matematika bersifat aplikatif dalam kehidupan sehari-hari. Selain itu menurut Turmudi (2008, hlm. 3) menyatakan bahwa, "(1) Matematika berkaitan erat dengan kehidupan sehari- hari; (2) Mempelajari matematika dapat membiasakan seseorang berpikir kritis, logis, serta dapat meningkatkan daya kreatifitasnya". Sehingga dengan segera siswa akan mampu menerapkan matematika dalam konteks yang berguna bagi siswa, baik dalam dunia kehidupannya ataupun dalam dunia kerja kelak.

Matematika dipelajari secara hirarkis dan spiral hal ini bertujuan untuk membangun pondasi pemahaman yang kuat sehingga siswa terampil dalam menyelesaian masalah-masalah Matematika. Matematika merupakan mata pelajaran yang wajib dipelajari di setiap tingkatan pendidikan mulai dari jenjang rendah sampai jenjang tinggi. Pada jenjang rendah, matematika dipelajari salah satunya di Sekolah Dasar. Hasil temuan berdasarkan kegiatan observasi dan wawancara menyebutkan bahwa mayoritas siswa menganggap matematika adalah mata pelajaran yang sulit khususnya siswa sekolah dasar. Hal ini mengakibatkan prestasi akademik dalam bidang matematika terbilang rendah dibuktikan dengan hasil wawancara dengan guru kelas IV pada salah satu SD Negeri di kabupaten Purwakarta yaitu hanya $25 \%$ siswa yang memahami matematika, sedangkan $75 \%$ siswa lainnya kurang memahami matematika. Hal ini diperkuat oleh temuan Trend in International Mathematics and Science Study (TIMSS) pada tahun 2015 yang menilai kemampuan Matematika dan Sains siswa kelas IV SD menunjukkan data yang sangat miris yaitu menempatkan Indonesia pada nomor 45 dari 50 negara, artinya kemampuan Matematika dan Sains siswa sangat rendah. Survei lain yang di lakukan oleh Programme for International Students Assessment (PISA) di tahun yang sama menunjukkan bahwa skor pencapaian siswa-siswi Indonesia pada pembelajaran Matematika berada pada posisi ke - 63 dari 69 negara yang dievaluasi. Hasil temuan TIMSS dan PISA ini memaparkan rendahnya kemampuan matematis siswa Indonesia.

Materi yang dianggap sulit dipahami oleh siswa Sekolah Dasar kelas IV yaitu perkalian, sedangkan perkalian merupakan hal dasar yang harus dikuasai siswa untuk mengantarkan siswa dalam memahami materi selanjutnya maupun materi dalam lintas bidang studi. Kesulitan memahami perkalian disebabkan karena dalam penyampaian materi oleh guru masih menggunakan metode hafalan, tanpa melibatkan langsung alat peraga penunjang perkalian, sehingga siswa tidak terlibat langsung dalam memecahkan masalah-masalah matematika dengan benda konkret yang dapat memudahkan mereka dalam menyelesaikan masalah perkalian, pada akhirnya kemampuan matematis tidak berkembang dengan baik.

Kondisi ini membuat peneliti termotivasi untuk mengembangkan salah satu model pembelajaran matematika melalui kombinasi beberapa model pembelajaran kooperatif. Hal tersebut menjadi satu solusi dari permasalahan yang telah dikemukakan. Besar harapan pembelajaran matematika menjadi lebih menyenangkan, sehingga siswa tidak lagi menganggap matematika sebagai mata pelajaran yang sulit dan dapat meningkatkan pemahaman matematis siswa.

Rumusan masalah berdasarkan latar belakang di atas yaitu (1) Bagaimanakah pengembangan model pembelajaran Trans Model Mathematic Education (T2ME) untuk meningkatkan keterampilan operasi perkalian dengan teknik SuBatSaGa di Sekolah Dasar?;

(2) Bagaiamana penerapan model pembelajaran Trans Model Mathematic Education (T2ME) untuk meningkatkan keterampilan operasi perkalian dengan teknik SuBatSaGa di Sekolah Dasar?". Tujuan dari penelitian ini yaitu untuk (1) Mengembangkan model pembelajaran Trans Model Mathematic Education (T2ME) untuk meningkatkan 
keterampilan operasi perkalian dengan teknik SuBatSaGa di Sekolah Dasar; (2) Penerapan model pembelajaran Trans Model Mathematic Education (T2ME) untuk meningkatkan keterampilan operasi perkalian dengan teknik SuBatSaGa di Sekolah Dasar.

Kajian teori yang mendukung penelitian terhadap pengembangan model pembelajaran T2ME yaitu model cooperative learning tipe Two Stay Two Stray (TSTS). Model cooperative learning tipe Two Stay Two Stray (TSTS) merupakan model pembelajaran kooperatif yang mengutamakan kegiatan berkelompok dalam menyelesaikan masalah yang diberikan oleh guru untuk kemudian hasilnya akan disampaikan berupa sebuah informasi oleh dua anggota kelompok kepada kelompok lain yang berkunjung dan dua anggota kelompok lainnya menerima informasi yang disampaikan oleh kelompok yang dikunjunginya. Beberapa ahli mengemukanan tentang pengertian model pembelajaran two stay two stray yaitu Lestari dan Yudhanegara (2014, hlm. 51) berpendapat bahwa, Model pembelajaran TSTS merupakan tipe pembelajaran kooperatif yang memberikan kesempatan kepada kelompok untuk berbagi pengetahuan dan pengalaman kepada kelompok lain dimana ada dua anggota kelompok atau lebih yang tinggal dan dua anggota kelompok atau lebih yang bertamu. Senada dengan pendapat di atas, Lie (2008, hlm. 61) berpendapat bahwa, "teknik two stay two stray dikembangkan oleh Spencer Kagan tahun 1992, teknik ini dapat diterapkan pada semua mata pelajaran dan untuk semua tingkatan usia anak didik". Langkah-langkah model pembelajaran TSTS dimulai dari Class Presentation, Grouping, Teamwork, Two Stay, Two Stray, dan Report Team.

Kajian teori lain yang mendukung dalam penelitian ini yaitu mengenai perkalian. Ada beberapa ahli yang menjelaskan mengenai konsep perkalian diantarnya yaitu Karim, dkk (1996, hlm. 101) menjelaskan bahwa,"perkalian merupakan penjumlahan berulang, Misalkan pada perkalian $4 \times 3$ dapat didefinisikan sebagai $3+3+3+3=12$ ", senada dengan pendapat di atas, Sutawidjaja (2011) mengungkapkan bahwa, perkalian adalah penjumlahan berganda dengan suku-suku yang sama. Sifat-sifat perkalian menurut Karim, dkk (1996, hlm. 103) yaitu, "sifat tertutup, sifat pertukaran atau komunitatif, sifat pengelompokan atau asosiatif, sifat unsur identitas dan sifat penyebaran atau distributif'. Berdasarkan pemaparan ahli, perkalian merupakan salah satu materi yang harus dipelajari dan dipahami oleh siswa Sekolah Dasar karena perkalian dijadikan sebagai landasan dalam mempelajari materi matematika selanjutnya dan digunakan pula dalam lintas bidang ilmu.

\section{METODE PENELITIAN}

Jenis penelitian ini yaitu penelitian dan pengembangan atau biasa disebut dengan Reseach and Develeopment $(R \& D)$. Adapun desain penelitian yang digunakan untuk menjaring data kuantitatif yaitu Pre-Eksperimental Design dengan tipe One-Group Pretest-Postest Design. Tipe One-Group Pretest-Postest Design diawali dengan pemberian pretes untuk mengetahui kemampuan awal siswa terhadap materi yang akan diteliti, kemudian diberikan perlakuan (treatment), dan diakhiri dengan pemberian postes untuk mengetahui kemampuan siswa setelah diberikan perlakuan. Sedangkan untuk menjaring data-data kualitatif digunakan instrumen non-test yaitu wawancara, angket, dan dokumentasi. Langkah-langkah penelitian dan pengembangan yang digunakan yaitu mengacu pada Borg dan Gall yang dinyatakan oleh Sugiyono (2017, hlm. 298) tersaji dalam bentuk tabel berikut: 
Tabel 1 Langkah-langkah penggunaan Metode Research and Development

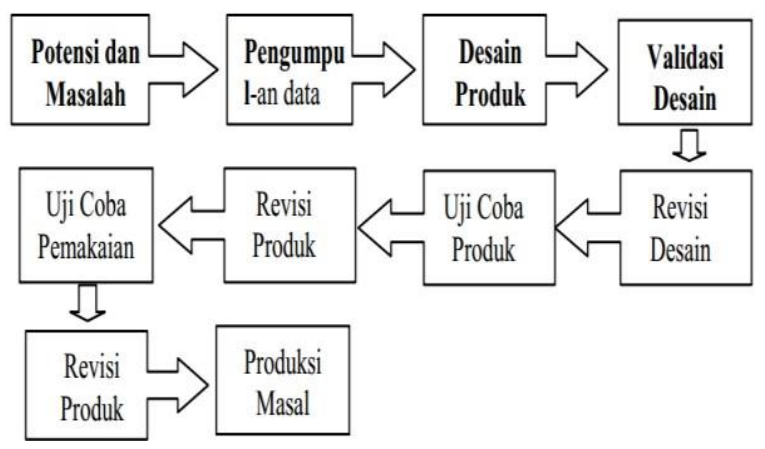

(Sugiyono, 2017, hlm. 298)

Penelitian ini baru terlaksana sampai pada tahap revisi produk dan rencana selanjutnya akan diteruskan uji coba produk sampai produksi masal. Berikut disajikan tabel desain prosedur penelitian Reseach and Develeopment $(\mathrm{R} \& \mathrm{D})$ tahap pengembangan.

Tabel 2 Desain Prosedur Penelitian Pengembangan

\begin{tabular}{|c|c|}
\hline \multirow{10}{*}{ 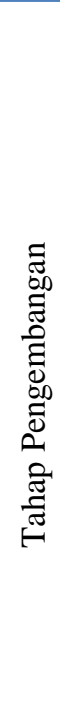 } & Mulai \\
\hline & Tahap persiapan \\
\hline & Observasi SD \\
\hline & $\begin{array}{l}\text { Identifikasi masalah dan } \\
\text { pengumpulan data }\end{array}$ \\
\hline & Perumusan masalah \\
\hline & Pembuatan desain produk \\
\hline & Revisi oleh pakar/ahli \\
\hline & $\begin{array}{l}\text { Penyusunan perangkat } \\
\text { pembelajaran, dan instrumen }\end{array}$ \\
\hline & Validasi oleh pakar/ahli \\
\hline & Revisi oleh pakar/ahli \\
\hline
\end{tabular}

\section{HASIL DAN PEMBAHASAN}

Pengembangan desain produk pada penelitian dan pengembangan ini yaitu Trans Model Mathematics Education (T2ME) dan teknik SuBatSaGa. Model dan teknik ini berawal dari sebuah permasalahan dalam pembelajaran Matematika khususnya materi perkalian. T2ME merupakan pengkombinasian model cooperative learning. Landasan pengembangan model pembelajaran T2ME yaitu model cooperative learning tipe Two Stray Two Stay (TSTS), dan model cooperative learning tipe Jigsaw. Kemudian model-model ini dikombinasikan dengan model cooperative learning lain yaitu Number Head Together (NHT), Inside Outside Circle (IOC), kirim salam, dan drill and practice Thorndike. Langkah-langkah model pembelajaran T2ME diadopsi dari langkah-langkah model yang telah terkombinasi, langkah yang diambil didasarkan pada keterkaitan antara langkah model yang satu dengan lainnya sehingga menghasilkan perpidahan yang harmonis pada penerapan model pembelajaran T2ME. Langkah- langkah pembelajaran T2ME secara lengkap tersaji pada tabel di bawah ini: 
Tabel 3 Langkah-langkah T2ME

\begin{tabular}{|c|l|}
\hline Langkah & \multicolumn{1}{|c|}{ Deskripsi } \\
\hline Pengelompokan & Pembentukan kelompok asal secara heterogen. \\
\hline $\begin{array}{c}\text { Penomoran dan } \\
\text { kelompok ahli }\end{array}$ & Pemberian nomor kepala dan kumpul kelompok ahli. \\
\hline Diskusi Ahli & Kelompok ahli berdiskusi. \\
\hline Pelaporan Hasil & $\begin{array}{l}\text { Kelompok ahli kembali ke kelompok asal dan } \\
\text { melaporkan hasil diskusi. }\end{array}$ \\
\hline $\begin{array}{c}\text { Berkubu Besar } \\
\text { Pengajuan } \\
\text { masalah }\end{array}$ & $\begin{array}{l}\text { Setiap 3 atau lebih kelompok berkumpul membentuk kubu } \\
\text { dan pemberian nama kubu. }\end{array}$ \\
\hline $\begin{array}{c}\text { Bertamu dan } \\
\text { Kirim salam }\end{array}$ & $\begin{array}{l}\text { Setiap kelompok mendelegasikan kelompoknya untuk } \\
\text { bertamu dan membuatjargon sebagai ucapan salam. }\end{array}$ \\
\hline $\begin{array}{c}\text { Laporan } \\
\text { kunjungan }\end{array}$ & Pelaporan hasil kunjungan kepada anggota kelompok asal. \\
\hline $\begin{array}{c}\text { Lingkar Main } \\
\text { Permainan }\end{array}$ & $\begin{array}{l}\text { Setiap kelompok dipecah ke dalam 2 kubu besar dan } \\
\text { membuat lingkaran besar dan kecil. }\end{array}$ \\
\hline $\begin{array}{l}\text { Lingkaran besar menghadap ke dalam dan lingkaran kecil } \\
\text { pertama lingkaran besar mengajukan pertanyaan, lingkaran } \\
\text { kecil diberi waktu untuk menjawab, dan dilakukan secara } \\
\text { bergantian.. }\end{array}$ \\
\hline and practice)
\end{tabular}

Langkah-langkah dalam T2ME melibatkan siswa siswa secara aktif serta berusaha membangun pemikiran siswa dengan cara bertukar ide atau hasil pemikiran dengan sistem peer teaching. Model pembelajaran T2ME menumbuhkan persaingan yang sehat antar kelompok karena dalam penerapannya setiap kelompok berusaha untuk mendapatkan penghargaan kelompok terbaik. Selain itu, model T2ME ini mengakomodasi beberapa gaya belajar siswa sehingga siswa akan lebih mudah menangkap pembelajaran.

Hasil lain dari penelitian pengembangan ini yaitu berupa teknik penyelesaian operasi perkalian puluhan dan ratusan. Teknik ini terdiri dari teknik Susun ke bawah, Batang Napier, Saringan, dan Garis (SuBatSaGa). Teknik ini dapat di jadikan sebagai solusi mudah dalam menyelesaikan masalah perkalian di sekolah dasar.

1) Teknik Susun Pendek ke Bawah

Teknik ini merupakan penyelesaian perkalian dengan bersusun kebawah.

87

hitung 7 × $5=35$, hanya ditulis angka 5, 3 disimpan kemudian

$15 \times$ kalikan $8 \times 5=40$, kemudian tambahkan $40+3=43$. Hitung 1 x 7

$435=7$, tulis angka 7 , kemudian kalikan 1 x $8=8$, tulis angka 8 , lalu

$87+$ jumlahkan angka-angka seperti pada gambar. 
2) Teknik Batang Napier

Penyelesaian perkalian dengan bantuan alat peraga batang perkalian (Baper).

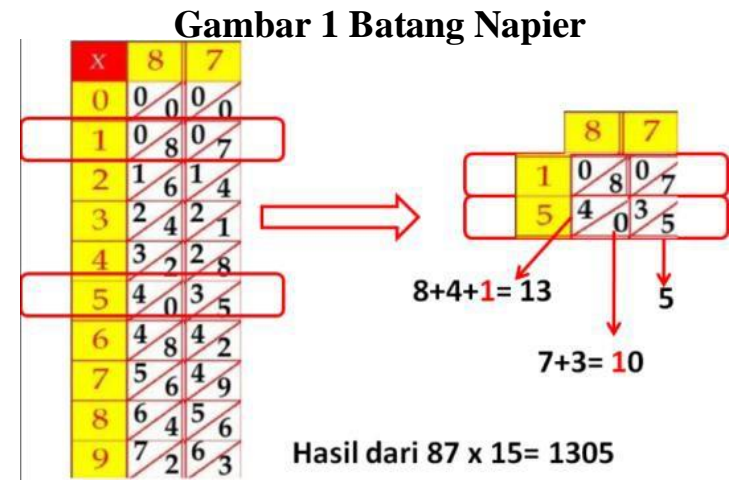

3) Teknik Saringan

Teknik perkalian yang menggunakan kisi untuk mengalikan dua angka atau lebih multi digit.

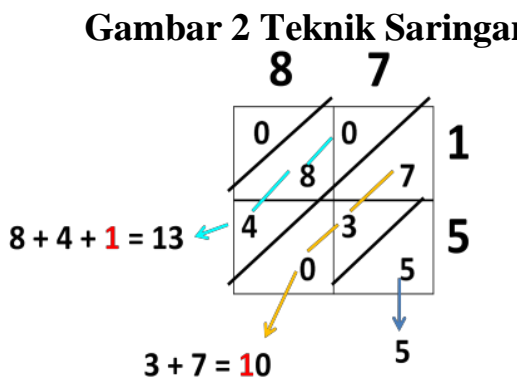

4) Teknik Garis

Hasil dari $87 \times 15=1305$

Teknik garis berasal dari Jepang, cara penyelesaian perkalian dengan teknik ini yaitu membuat garis diagonal sebanyak digit angka pertama, digit angka kedua dan seterusnya, lanjut membuat garis diagonal berlawanan arah sebanyak digit angka pertama di pengalih berikutnya.

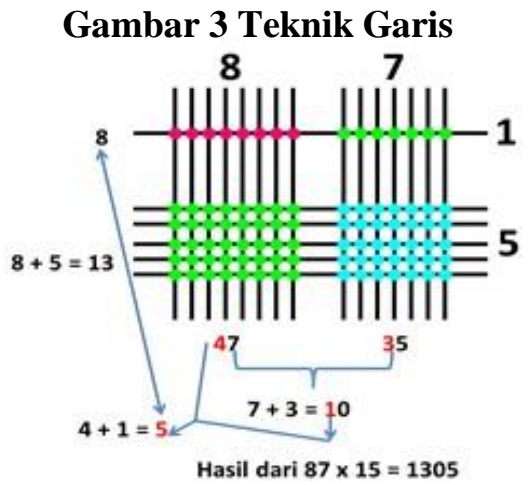

Teknik-teknik perkalian tersebut pada dasarnya memberikan jalan mudah bagi siswa untuk menyelesaikan masalah-masalaha perkalian serta agar siswa mempunyai keterampilan dalam memecahkan operasi hitung perkalian dengan mudah tanpa harus dibebankan dengan hafalan. Teknik tersebut juga dapat mengantarkan siswa dari tahap concrete sampai kepada tahap abstract, sehingga siswa lebih mudah dalam memahami konsep matematis. 
Teori belajar yang mendukung penelitian T2ME dan teknik SuBatSaGa yaitu teori belajar Piaget, Maulana (2011, hlm. 70) menyatakan bahwa: "tahapan perkembangan kognitif menurut Piaget yaitu 1) tahap sensori motor (lahir-2 tahun; 2) tahap praoperasional (2-7 tahun; 3) tahap operasional konkret (7-12 tahun); dan 4) tahap operasi formal (12-dewasa)". Pada teori Jean Piaget diperoleh tentang perkembangan kognitif anak usia Sekolah Dasar yaitu tahap operasional konkret. Oleh karenanya, pada proses pembelajaran harus menghadirkan benda-benda konkret maupun benda manipulasi dalam kegiatan pembelajaran agar siswa lebih mudah memahami materi pembelajaran yag diberikan. Teori lain yang mendukung pengembangan model pembelajaran T2ME dan teknik SuBatSaGa yaitu teori Ausubel. Teori ini dikenal dengan teori belajar bermakna. Maulana (2011, hlm. 64) memaparkan bahwa, "belajar memahami apa yang telah diperoleh, kemudian dikaitkan dengan pembelajaran lain sehingga belajarnya lebih mengerti".

\section{KESIMPULAN}

Model pembelajaran T2ME merupakan perpaduan beberapa model cooperative learning yang bertujuan untuk mengaktifkan siswa dalam proses pembelajaran. Landasan teori T2ME yaitu teori perkembangan kognitif Piaget dan teori berlajar bermakna Ausubel. Model T2ME ini mengakomodasi beberapa gaya belajar siswa sehingga sebagian besar siswa dapat memahami materi dengan baik.

Matematika menuntut siswa untuk mempunyai keterampilan pemecahan masalah, salah satunya yaitu keterampilan operasi perkalian. Perkalian dapat dipecahkan melalui beberapa teknik diantaranya yaitu teknik Susun ke bawah, Batang Napier, Saringan, dan Garis. Teknik di atas dapat dijadikan sebagai solusi mudah dalam perkalian puluhan dan ratusan.

\section{REFERENSI}

A, K., \& Muchtar, D. (1996). Pendidikan Matematika 1. Malang: Depdikbud.

Lie, A. (2008). Cooperative Learning. Jakarta: PT Gramedia.

Maulana. (2011). Keilmuan dan Pembelajaran Matematika. Bandung: Royyan Press.

Rahmawati. (2015). Seminar Hasil TIMSS.

Sugiyono. (2017). Metode Penelitian Kuantitatif, Kualitatif, dan R\&D. Bandung: Alfabeta.

Sutawidjaja, A. (2011). Matematika-Studi dan Pengajaran. Jakarta: Universitas Terbuka.

Turmudi. (2008). Landasan Filsafat dan Teori Pembelajaran Matematika (Berparadigma Eksploatif dan Investigatif). Jakarta: Leuser Cipta Pustaka.

Yudhanegara, M., \& Lestari, K. E. (2014). Penelitian Pendidikan Matematika. Bandung: Refika Aditama. 